All letters are subject to editing and may be shortened. Letters should be sent to the BJGP office by e-mail in the first instance, addressed to

journal@rcgp.org.uk (please include your postal address). Alternatively, they may be sent by post as an MS Word or plain text version on CD or DVD. We regret that we cannot notify authors regarding publication. Letters not published in the Journal may be posted online on our Discussion Forum. For instructions please visit: http://www.rcgp.org.uk/bjgp-discuss

\section{Learning disability}

It is quite natural that key experiences from our family life show transference to our professional relationships. I certainly draw on personal feelings from childhood to aid empathy for children receiving health care. However, such anecdotal recollections ${ }^{1}$ can give an unreliable picture of general systems, such as primary medical care for people with learning disabilities, across Britain.

Inequalities in GPs' involvement with these patients were first drawn to my attention while collecting 1-month diaries of patient contacts from $40 \mathrm{GPs}$, for the ICD-10 primary health care field trial. ${ }^{2}$ Most GPs saw no people with learning disabilities (code F70) in that month, although a minority had several patients (mean 0.28 cases per month). ${ }^{3}$ Based on population prevalence, one would expect about one case per day. About the same time, we found that the women with learning disabilities living in the community who managed to see their GP (for a cervical smear) often had unhappy experiences that they were reluctant to

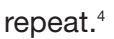

Fitzpatrick ${ }^{1}$ is off target comparing this problem to prejudice like racism (marked by xenophobic fear or hatred): a decade's primary care research has confirmed that indifference really is the problem, with most of the population with disabilities invisible to clinicians. We found staff in schools very open to assessing and checking the health needs associated with learning disabilities, when the 'health facilitation' proposed by the Department of Health was introduced. ${ }^{5}$ A minority of GPs responded very positively when we tried to introduce health facilitation to general practice. ${ }^{6}$ Their patients (in varied settings) gained individual Health Action Plans, including development of some quite new services. Sadly, a substantial majority of GPs were not interested in the local residents with learning disabilities, let alone prepared to initiate seeing those patients annually.

Such indifference is not just found frequently in medical practice. It is also common in our academic ivory towers. ${ }^{7}$

\section{Woody Caan,}

Department of Child \& Family Health, Anglia Ruskin University, Cambridge.

E-mail: woody.caan@anglia.ac.uk

\section{REFERENCES}

1. Fitzpatrick M. Learning difficulties scandal. Br J Gen Pract 2008; 58(557): 899 .

2. Ustun TB, Goldberg D, Cooper J, et al. New classification for mental disorders with management guidelines for use in primary care: ICD-10 PHC chapter five. Br J Gen Pract 1995; 45(393): 211-215.

3. Caan W, Hampton-Matthews S. One from the heart for people with a learning disability. Br J Nurs 1999; 8(2): 97-100.

4. Broughton S, Thomson K. Women with learning disabilities: risk behaviours and experiences of the cervical smear test. J Adv Nurs 2000; 32(4): 905-912.

5. Caan W, Lutchmiah J, Thomson K, Toocaram J. Health facilitation in primary care. Prim Health Care Res Dev 2005; 6: 348-356.

6. Thomson K, Gripton J, Lutchmiah J, Caan W. Health facilitation in primary care seen from practice and education. Br J Nurs 2007; 16(18): 1156-1160

7. Caan W. Shame on the academic community too. Lancet 2008; 372(9647): 1384.

DOI: 10.3399/bjgp09X419556

\section{Author's response}

The parallel between racial prejudice and the treatment of people with learning disabilities is not mine but the central theme of the 2007 Mencap report which blames 'institutional discrimination' in the NHS for the deaths of six patients. This concept was adopted from the 1999
Macpherson report which attributed the failure to prosecute the killers of Stephen Lawrence to 'institutional discrimination' within the Metropolitan Police. Although there is a long history of racial discrimination in Britain, it is doubtful whether this remains a significant force now that 'anti-racism' has become the official ideology leading to extensive police activity on the streets, on the football terraces, and in workplaces.

No doubt people with learning disabilities, like many other people, suffer from neglect and sub-standard treatment in the NHS. What I doubt is whether they suffer from systematic discrimination, and I dispute the value of trying to tackle the specific problems they face by promoting this posture of victimhood and grievance.

It is not surprising that people who have difficulties in articulating their demands experience difficulties in gaining access to general practice: traditionally a demand-led service. There are real problems in providing satisfactory medical care for people with learning difficulties - including the mediating role of family and professional carers - but these are not improved by the sort of posturing and token gestures (like annual health checks) currently being introduced.

\section{Mike Fitzpatrick,}

Barton House Health Centre, 233 Albion Road, London N16 9JT. E-mail: fitz@easynet.co.uk

DOI: 10.3399/bjgp09X419565

\section{Usual care in back pain trials}

In the November issue of the BJGP, 
Somerville et al report an interesting systematic review of usual care in low back pain primary care trials. ${ }^{1}$ They highlight the variability that currently exists in the usual care packages, which function as the comparator treatment in many trials, and point out that the content of treatment in this arm is often inadequately described. They draw our attention to the difficulties associated with the interpretation of results when this comparator treatment is poorly described. We hope their message does not fall on deaf ears.

Notwithstanding this, we feel that their interpretation that the speed at which the Roland Morris Disability Questionnaire (RMDQ) score changes over time is dependent on the duration of low back pain, may be inaccurate. The clinical trajectories in several acute/sub-acute trial arms to trajectories from two small chronic low back pain trials were compared and Somerville et al note a more rapidly improving trajectory in the acute/sub-acute arms. ${ }^{2,3}$ Meng et al's report ${ }^{2}$ on a trial of acupuncture $(n=24)$ for chronic low back pain in older patients describes follow-up results at 2, 6, and 9 weeks; rather than the 30 week follow-up period indicated by Somerville et al.

Licciardone's report of a trial of osteopathic manipulation $(n=20)^{3}$ did not provide point estimates for follow-up RMDQ scores in their usual care group; rather, it was stated 'there was no significant decrease'. This was represented as Figure 1 in Somerville et al's report as a stable trajectory. ${ }^{1}$

We have done a new analysis of data from the UK BEAM trial ${ }^{4}$ (Brealey et $a^{5}{ }^{5}$ in the original paper), extracting data on outcomes for those in the usual care group of this trial with pain lasting for more than 3 months $(n=205)$.

Furthermore, we obtained data from the usual care arm of Licciardone et al's trial of osteopathic manipulation (thanks to John Licciardone). For completeness, we present a figure including these data (Figure 1).

The usual care arm in the UK BEAM trial was nearly eight times the size of the

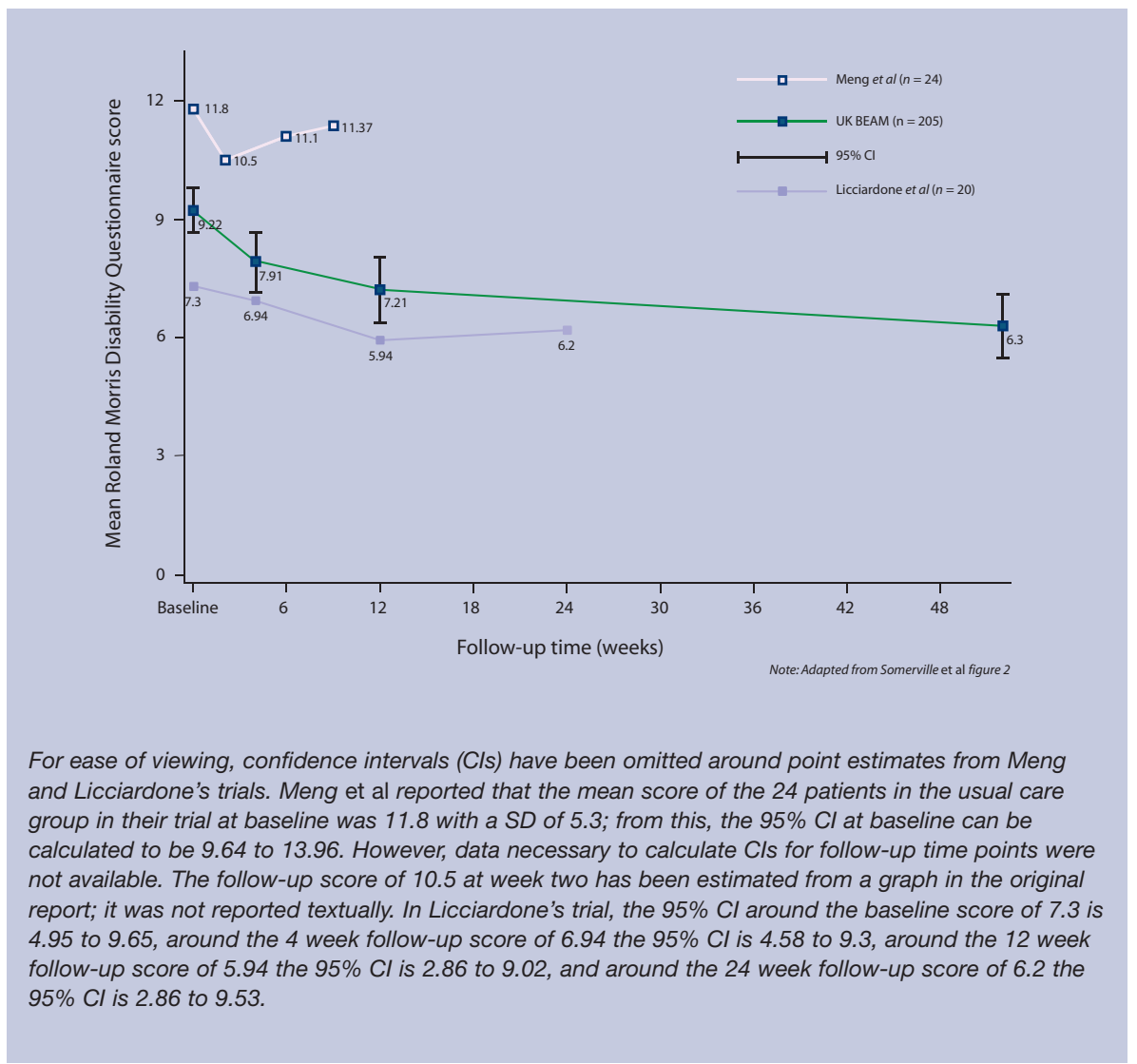

two previously included studies combined. Data from patients with chronic pain show a markedly different trajectory from those described in Somerville et al's report (Figures 1 and 2). It more closely mimics the acute/subacute trajectories they presented. In contrast to their conclusion, we conclude that patients in usual care arms are likely to improve in trials of both acute and chronic back pain.

\section{Robert Froud,}

Barts \& The London School of Medicine and Dentistry, Queen Mary University of London, Institute of Health Sciences Education, London E1 2AD. E-mail: r.j.froud@qmul.ac.uk

\section{Martin Underwood,}

Warwick Clinical Trials Unit, Warwick Medical School, Gibbet Hill Road, Coventry CV4 7AL.

\section{REFERENCES}

1. Somerville S, Hay E, Lewis M, et al. Content and outcome of usual primary care for back pain: a systematic review. Br J Gen Pract 2008; 58(556): 790-797, i-vi.

2. Meng CF, Wang D, Ngeow J, et al. Acupuncture for chronic low back pain in older patients: a randomized, controlled trial. Rheumatology (Oxford) 2003; 42(12): 1508-1517.

3. Licciardone JC, Stoll ST, Fulda KG, et al. Osteopathic manipulative treatment for chronic low back pain: a randomized controlled trial. Spine 2003; 28(13): 1355-1362.

4. UK BEAM Trial Team. United Kingdom back pain exercise and manipulation (UK BEAM) randomised trial: effectiveness of physical treatments for back pain in primary care. BMJ 2004; 329(7479): 1377.

5. Brealey S, Burton K, Coulton S, et al. UK Back pain Exercise and Manipulation (UK BEAM) trial national randomised trial of physical treatments for back pain in primary care: objectives, design and interventions. BMC Health Services Research 2003; 3(1): 16 .

DOI: 10.3399/bjgp09X419574

\section{Author's response}

I welcome the comments and additional data provided by Froud and Underwood. I quite agree with them that the endpoint for data collection in Meng et al's report' was at 9 weeks rather than 30 weeks as represented in the published version of in Figure $2 b$ of our paper. ${ }^{2}$ The version of our paper that was accepted for 